\title{
Cardiac Vagal Tone Predicts Attentional Engagement To and Disengagement From Fearful Faces
}

\author{
Gewnhi Park \\ Azusa Pacific University
}

Jay J. Van Bavel
New York University

\author{
Michael W. Vasey and Julian F. Thayer \\ The Ohio State University
}

\begin{abstract}
The current research examines individual differences in flexible emotional attention. In two experiments, we investigated the relationship between individual differences in cardiac vagal tone and top-down and bottom-up processes associated with emotional attention. To help determine the role of cortical and subcortical mechanisms underlying top-down and bottom-up emotional attention, fearful faces at broad, high, and low spatial frequency were presented as cues that triggered either exogenous or endogenous orienting. Participants with lower heart rate variability (HRV) exhibited faster attentional engagement to low-spatial-frequency fearful faces at short stimulus-onset asynchronies, but showed delayed attentional disengagement from high-spatial-frequency fearful faces at long stimulus-onset asynchronies in contrast to participants with higher HRV. This research suggests that cardiac vagal tone is associated with more adaptive top-down and bottom-up modulation of emotional attention. Implications for various affective disorders, including depression, anxiety disorders, and posttraumatic stress disorder, are discussed.
\end{abstract}

Keywords: cardiac vagal tone, top-down, bottom-up, emotional attention

A growing body of research suggests that both bottom-up and top-down processes play an important role in processing affectively significant stimuli and generating emotional experiences (Cunningham, Zelazo, Packer, \& Van Bavel, 2007; Hsu \& Pessoa, 2007; Ochsner et al., 2009; Pessoa, Kastner, \& Ungerleider, 2002; Van Bavel, Xiao, \& Cunningham, 2012; Vuilleumier \& Huang, 2009). As such, successful self-regulation depends on the ability to achieve an optimal balance between top-down and bottom-up influences in a given situation (Johnstone, van Reekum, Urry, Kalin, \& Davidson, 2007; Ochsner et al., 2009). Indeed, there is extensive evidence suggesting that the failure of emotional selfregulation is an important characteristic of many forms of psychopathology. For example, anxiety and depression are characterized by the dysfunctional processing of affective stimuli (American Psychiatric Association, 1994; Cisler \& Koster, 2010; Mathews, Mackintosh, \& Fulcher, 1997). However, relatively little is known about the relationship between self-regulation and the integration of top-down and bottom-up processing associated with emotional attention (Ochsner \& Gross, 2005). The current research examined individual differences in cardiac vagal tone and the top-down and bottom-up processes that underlie flexible emotional attention.

Gewnhi Park, Department of Psychology, Azusa Pacific University; Jay J. Van Bavel, Department of Psychology, New York University; Michael W. Vasey and Julian F. Thayer, Department of Psychology, The Ohio State University.

Correspondence concerning this article should be addressed to Gewnhi Park, Department of Psychology, Azusa Pacific University, 901 E. Alosta Avenue, Azusa, CA 91702. E-mail: flyingbluesky.park@gmail.com

\section{The Neurovisceral Integration Model and Heart Rate Variability}

According to the neurovisceral integration model (Thayer \& Lane, 2000; Thayer, Hansen, Saus-Rose, \& Johnsen, 2009), prefrontal cortical structures, including orbitofrontal cortex (OFC) and medial prefrontal cortex (mPFC), exert a tonic inhibitory control on subcortical structures including the central nucleus of the amygdala $(\mathrm{CeA})$, which plays an important role in modulating cardiovascular, autonomic, and endocrine responses (Thayer \& Lane, 2000; Thayer et al., 2009). Under normal circumstances, sympathoexcitatory subcortical circuits are under tonic control of prefrontal inhibitory activity (Thayer et al., 2009). Under threatening and uncertain situations, the prefrontal cortex unleashes its control and lets sympathoexcitatory subcortical circuits make autonomic and prepotent responses. However, the malfunctioning of prefrontal inhibitory control under normal circumstances can lead to hyperactive subcortical activity, which results in prolonged activation of defensive behavior mechanisms, such as hypervigilance and perseverative cognition (Thayer \& Lane, 2000; Thayer et al., 2009). Therefore, the prefrontal inhibitory control is vital for an organism to make flexible, adaptive responses to meet various situational demands (Thayer et al., 2009; Thayer \& Ruiz-Padial, 2006). Research has shown that neutral circuits bidirectly connecting the prefrontal cortex with subcortical structures are linked with the heart via the vagus nerve (for reviews, see Benarroch, 1993; Berntson et al., 1997; Ellis \& Thayer, 2010; Thayer et al., 2009). Evidence has shown that the functioning of inhibitory prefrontal control is associated with the vagal nerve that provides inhibitory inputs to the heart and regulates metabolic responses to the environment (Thayer \& Lane, 2000; Thayer et al., 2009; see also 
Porges, 2003). Robust vagal regulation on the heart indicates highly functional prefrontal inhibition on subcortical structures, which allows for effective cognitive, emotional, and autonomic self-regulation (see Friedman, 2007; Porges, 1991; Thayer \& Friedman, 2004; Thayer et al., 2009).

Heart rate variability (HRV) refers to the differences in beat-tobeat alterations in heart rate and can separate the relative contribution of sympathetic and vagal system on the heart (Berntson et al., 1997; Task Force of the European Society of Cardiology and the North American Society of Pacing and Electrophysiology, 1996, hereafter, "Task Force"; Thayer \& Lane, 2000). Over the past few years, several neuroimaging and pharmacological studies have provided evidence that vagally mediated HRV is related to the inhibitory neural circuits that play an important role in selfregulation (Ahern et al., 2001; Lane et al., 2009). High vagally mediated resting HRV (henceforth referred to as high HRV) is associated with highly functional prefrontal inhibitory control over subcortical structures, which allows organisms to make situationally adaptive responses, such as distinguishing between safety and threat (Thayer \& Lane, 2000; Thayer et al., 2009). In contrast, low vagally mediated resting $\mathrm{HRV}$ (henceforth referred to as low HRV) is associated with reduced prefrontal control over subcortical structures such as the amygdala (Thayer \& Lane, 2000; Thayer et al., 2009). As a result, low HRV is associated with hyperactive subcortical activity, which results in poor self-regulatory functions, such as making hypervigilant responses (Thayer \& Lane, 2000; Thayer et al., 2009). A number of studies have linked low HRV with a higher incidence of psychiatric disorders (e.g., panic disorder and generalized anxiety disorders; Friedman, 2007; Friedman \& Thayer, 1998; Thayer \& Lane, 2000). In the current research, we examine the relation between HRV and top-down and bottom-up attention mechanisms to fearful faces at different spatial frequencies.

\section{Attentional Orienting}

Posner's spatial cuing paradigm (Posner \& Petersen, 1990; Posner \& Rothbart, 2007) has been used to investigate how different attentional components respond to affectively significant stimuli (Pourtois \& Vuilleumier, 2006; Vuilleumier, 2005). In the spatial cueing task (Bartolomeo, Sieroff, Decaix, \& Chokron, 2001; Posner \& Petersen, 1990; Posner \& Rothbart, 2007), a target is preceded by a cue that either correctly predicts the location in which a subsequent target will appear (valid) or not (invalid; Posner \& Petersen, 1990; Posner \& Rothbart, 2007). Based on extensive studies of the spatial cueing task, Posner and others (Bartolomeo et al., 2001; Posner \& Petersen, 1990; Posner \& Rothbart, 2007) have identified two different types of attentional orienting. Exogenous orienting is characterized as a bottom-up, reflexive orienting mode that is associated with neural activity of the posterior attention system, which includes the superior parietal cortex, pulvinar, and superior colliculus (Berger, Henik, \& Rafal, 2005; Huang-Pollock \& Jigg, 2003; Posner \& Petersen, 1990; Posner \& Rothbart, 2007). Exogenous orienting is typically observed when the duration between the onset of a cue and the onset of a target (stimulus onset asynchrony [SOA]) is short, peaking at $150 \mathrm{~ms}$. Endogenous orienting is characterized as a top-down, voluntary attentional mode, and is associated with the anterior attention system, which includes the anterior cingulate and pre- frontal cortex (Berger et al., 2005; Huang-Pollock \& Jigg, 2003; Posner \& Petersen, 1990; Posner \& Rothbart, 2007). Endogenous orienting is typically observed when the majority of the cues are valid at long SOAs (e.g., > $300 \mathrm{~ms}$ ). People notice that a target is more likely to appear where a preceding cue is presented and strategically use voluntary attentional control (Bartolomeo et al., 2001; Coull, Frith, Buchel, \& Nobre, 2000).

Behavioral and neuroimaging research demonstrates that emotional information is prioritized: Emotional stimuli grab attention, are detected more easily, and are more likely to reach awareness than neutral stimuli-a phenomenon termed emotional attention (Pourtois \& Vuilleumier, 2006; see Vuilleumier \& Brosch, 2009, for a review). Most empirical studies focus on rapid attention capture by threatening stimuli, such as angry faces (Bar-Haim, Lamy, Pergamin, Bakermans-Kranenburg, \& van Ijzendoorn, 2007). For instance, when fearful faces are used as cues in an emotional cuing task, people are faster to detect targets in valid trials (attentional engagement) and are slower to disengage their attention from cues and detect targets in invalid trials (attentional disengagement) compared with neutral stimuli. Neuroimaging studies have shown that fearful face cues facilitate exogenous attentional engagement to targets through neural mechanisms of the posterior attentional system (Pourtois, Dan, Grandjean, Sander, $\&$ Vuilleumier, 2005). In contrast, delayed attentional disengagement from fearful face cues in invalid trials is associated with reduced activity of the posterior parietal cortex and simultaneously increased activity of the ventromedial prefrontal cortex, including the rostral anterior cingulate cortex (Pourtois \& Vuilleumier, 2006). Therefore, both attentional engagement to fearful face cues and exogenous attention are associated with activity in subcortical neural structures. In contrast, attentional disengagement from fearful face cues and endogenous attention are associated with activity in frontoparietal neural structures. In the current research, we defined attentional engagement to fearful face cues under the exogenous attention mode as a bottom-up mode of emotional attention, and attentional disengagement from fearful face cues under the endogenous mode as a top-down mode of emotional attention. We examined the relationship between HRV and topdown and bottom-up aspects of emotional attention. To further isolate the neurocognitive mechanisms, we presented faces at high and low spatial frequencies.

\section{The Role of Spatial Frequency in Face Perception}

Recent neuroimaging studies have shown that fearful faces at high and low spatial frequency ranges are processed distinctively via cortical or subcortical visual channels, respectively (Vuilleumier, Armony, Driver, \& Dolan, 2003; Winston, Vuilleumier, \& Dolan, 2003). Spatial frequency is described by the energy distribution in the scale specified as the number of cycles per degree of visual angle and/or the number of cycles per image (Morrison \& Schyns, 2001; Parker, Lishman, \& Hughes, 1996). Broad spatial frequency (BSF) images contain all spatial frequency ranges and can be filtered to contain either high spatial frequency (HSF) or low spatial frequency (LSF; Holmes, Green, \& Vuilleumier, 2005; Vuilleumier et al., 2003; see Figure 1).

LSF information is conveyed via the magnocellular pathway, which rapidly mediates perception of depth, motion, and lowcontrast black-and-white information (Livingstone \& Hubel, 1988; 


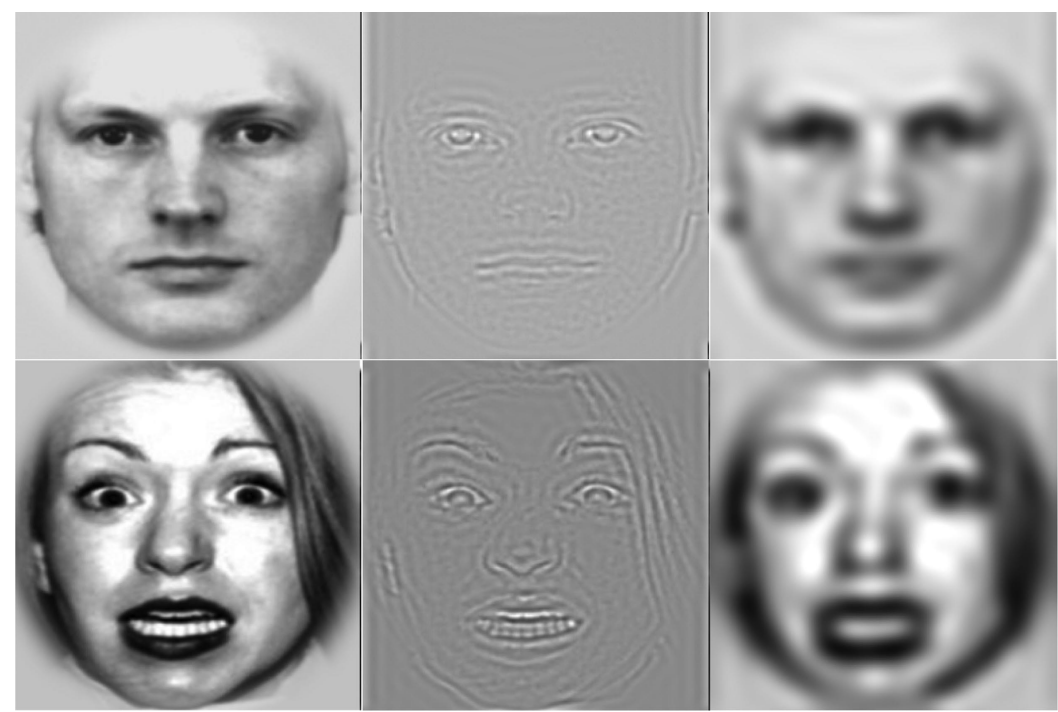

Figure 1. Example stimuli. Normal broad spatial frequency (BSF) fearful and neutral faces (left column), high spatial frequency (HSF) faces (middle column), and low spatial frequency (LSF) faces (right column).

Merigan \& Maunsell, 1993; Nieuwenhuis, Jepma, Fors, \& Olivers, 2008; Palermo \& Rhodes, 2007; Vuilleumier et al., 2003). Several researchers have argued that LSF fearful faces, in particular, are processed in a rapid, but coarse, fashion by the phylogenetically old retinotectal pathway (Livingstone \& Hubel, 1988; Merigan \& Maunsell, 1993; Nieuwenhuis et al., 2008; Palermo \& Rhodes, 2007; Vuilleumier et al., 2003). In this pathway, information is conveyed through the superior colliculus and pulvinar nucleus of the thalamus to the amygdala and subcortical mechanisms of the face perception network (Livingstone \& Hubel, 1988; Merigan \& Maunsell, 1993; Nieuwenhuis et al., 2008; Palermo \& Rhodes, 2007; Vuilleumier et al., 2003). Research has indicated that amygdala activity is greater for fearful faces than neutral faces at LSF, but not at HSF (Vuilleumier et al., 2003). The amygdala, then, may relay LSF fearful information to posterior regions mediating attentional engagement (Pourtois \& Vuilleumier, 2006). Indeed, evidence indicates that people's attention is quickly drawn to LSF fearful versus neutral faces, whereas no such advantage is found for HSF fearful versus neutral faces (Holmes et al., 2005). Furthermore, a recent study reported that LSF fearful faces elicited faster saccadic responses compared with LSF happy faces (Bannerman, Hibbard, Chalmers, \& Sahraie, 2012). These results suggest that attentional engagement to LSF fearful faces may be mediated by subcortical mechanisms.

HSF information is mainly carried through the parvocellular pathway, which mediates perception of color and contrast (Livingstone \& Hubel, 1988; Merigan \& Maunsell, 1993; Nieuwenhuis et al., 2008; Palermo \& Rhodes, 2007; Vuilleumier et al., 2003). Due to thin nerve fibers, the parvocellular pathway transfers information slowly, but with high resolution (Merigan \& Maunsell, 1993; Vuilleumier et al., 2003). HSF fearful faces are processed through cortical mechanisms, including the prefrontal cortex. For example, activity in ventral visual cortical areas, including the bilateral fusiform and the inferior temporo-occipital cortex, was greater for HSF faces than LSF faces (Vuilleumier et al., 2003). In addition, HSF fearful faces elicited greater responses in the pos- terior cingulate, the motor cortex, the $\mathrm{mPFC}$, and the lateral $\mathrm{OFC}$ (Winston et al., 2003). Furthermore, our recent study showed that high HRV was related to superior visual perception of HSF fearful faces, which was modulated by top-down task goals (Park, Van Bavel, Egan, Vasey, \& Thayer, 2012a). These results suggest that attentional disengagement from HSF fearful faces may be mediated by prefrontal mechanisms.

\section{Overview of the Current Research}

The goal of the current research is to investigate the relationship between individual differences in cardiac vagal tone and the topdown and bottom-up processes that underlie flexible emotional attention. As an effective indicator of self-regulation, individual differences in cardiac vagal tone should be associated with the adaptive engagement of top-down and bottom-up attentional processes. To dissociate the top-down and bottom-up mechanisms of emotional attention, we systematically varied SOAs to evoke endogenous or exogenous attentional modes. When the majority of cues $(80 \%)$ are valid, bottom-up, exogenous attentional orienting occurs at short SOAs and top-down and endogenous attentional orienting occurs at long SOAs (Bartolomeo et al., 2001; Müller \& Rabbitt, 1989). In Experiment 1, we presented face cues for 250 ms to evoke bottom-up, exogenous attention (Fox, Russo, Bowles, \& Dutton, 2001). In Experiment 2, we used longer SOAs (960 ms) to evoke top-down, endogenous attention (Bartolomeo et al., 2001; Coull et al., 2000).

We predicted that participants with high HRV_indicating highly functional emotional and cognitive self-regulation-would show more adaptive patterns of emotional attention than participants with low HRV (Park, Vasey, Van Bavel, \& Thayer, 2013). To help isolate the neurocognitive mechanisms underlying affective flexibility, we used fearful faces at high and low spatial frequencies. We predicted that people with low HRV—characterized by hyperactive amygdala activity-would show faster attentional engagement to LSF fearful faces under a bottom-up, exog- 
enous attentional mode compared with people with high HRV. Faster engagement to fearful faces is often considered dysfunctional because it indicates hypervigilance to threatening stimuli. For example, people with high anxiety are characterized by faster attentional engagement to threatening stimuli at shorter SOAs (Cisler \& Koster, 2010; Koster, Crombez, Verschuere, Damme, \& Wiersema, 2006; Mathews et al., 1997). On the other hand, people with low HRV - who may possess impaired prefrontal functionshould have difficulty disengaging attention from HSF fearful faces compared with people with high HRV under the top-down, endogenous attentional mode. Delayed attentional disengagement from threatening stimuli can be considered dysfunctional because it indicates the failure to inhibit attention from threatening stimuli (Fox, Russo, \& Dutton, 2002; Verkuil, Brosschot, Putman, \& Thayer, 2009). This pattern of results would suggest that cardiac vagal tone is associated with flexibility of emotional attention.

\section{Experiment 1: Cardiac Vagal Tone and Exogenous Emotional Attention}

In Experiment 1, we examined the relationship between individual differences in HRV and attentional engagement for LSF fearful faces under the bottom-up, exogenous attentional mode. We hypothesized that participants with low HRV would show faster attentional engagement toward LSF fearful faces compared with participants with high HRV at short (e.g., $250 \mathrm{~ms}$ ) SOAs. However, because attentional disengagement from HSF fearful faces requires top-down processing, we did not predict a relationship between HRV and attentional disengagement from HSF fearful faces in the exogenous attentional mode.

\section{Method}

Participants. Thirty-two female undergraduate students (mean age $=20$ years) participated in the study for partial course credit. ${ }^{1}$ All participants were nonsmokers and were asked to refrain from alcohol, drug use, and caffeinated beverages for $4 \mathrm{hr}$ prior to participation (Hansen, Johnsen, \& Thayer, 2003). All participants had normal or corrected-to-normal vision (20/20 visual acuity). People with a history of vision disorders or dysfunctions, neurological or psychiatric disorders, cardiovascular disorders, or medical conditions, such as diabetes, were excluded from this experiment. We excluded the data from three participants who had more than $15 \%$ of trials missing due to errors and outliers.

Procedure. All participants were tested individually in a dimly lit room. They were brought to the lab and three surface electrodes were attached - the negative electrode below the right collar bone, the positive electrode below the left rib cage, and the ground electrode below the right rib cage-to obtain electrocardiographic data. After placement of electrodes, resting HRV was recorded for $5 \mathrm{~min}$. Participants then performed the emotional spatial cuing task (Koster, Crombez, Verschuere, \& Houwer, 2004; Koster et al., 2006).

The emotional spatial cuing task. On each trial, a white fixation cross ("+") was presented in the middle of the screen, and two gray boxes were presented-one on the left and the other on the right of the fixation point (see Figure 2). These boxes measured $6^{\circ}$ horizontally and $6^{\circ}$ vertically at a viewing distance of $160 \mathrm{~cm}$. The middle of these boxes was located at a distance of $6^{\circ}$ from the

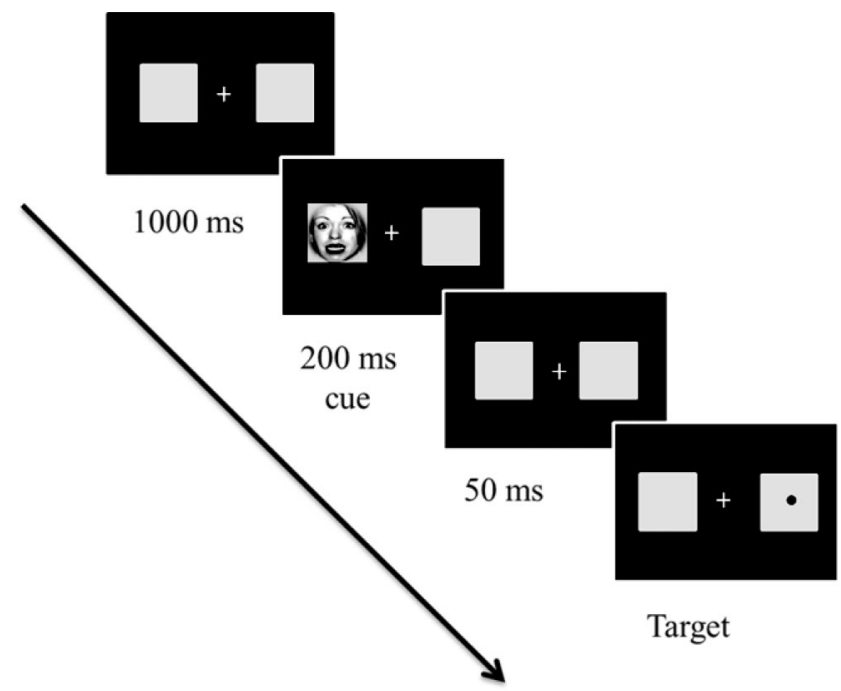

Figure 2. Sample trial in Experiment 1. The cues and targets were equally likely to appear on the right or left of fixation. However, $80 \%$ of trials were valid (96 trials) and $20 \%$ of the trials were invalid (24 trials). The initial fixation display appeared for 1,000 ms. Then, cues, which were either fearful or neutral faces created at broad, high, and low spatial frequency, appeared for $250 \mathrm{~ms}$. After a 50-ms delay with the initial fixation display, a target circle appeared in the center of the left or right box until the participant responded (or until 2,000 ms elapsed). Stimuli are not drawn to scale.

fixation point. The target that participants had to detect was a black circle, subtending a visual angle of $0.6^{\circ}$ across the diameter. The initial fixation display was presented for $1,000 \mathrm{~ms}$. Then, a face cue was presented either in a left- or right-side gray box for 250 ms. After a 50-ms delay, a target circle appeared at the center of either the left- or right-side boxes until the participants responded (or until 2,000 ms elapsed). There was an intertrial interval of 1000 ms. All stimuli were presented on a black background.

Participants were told that a cue preceding a target did not predict where the target would appear. Therefore, they should ignore the face cues and keep their eyes focused on the fixation point on the center of the screen. They were instructed to indicate where targets appeared by pressing " $Z$ " for a target on the left box or " $\mathrm{M}$ " for a target on the right as quickly and accurately as possible. Each participant completed three blocks of trials with different spatial frequencies (BSF, HSF, LSF; see Figure 1), and blocks were presented in counterbalanced order. Each block consisted of 12 practice trials and 120 experimental trials with faces of the same spatial frequency. In each block, $80 \%$ of experimental trials were valid (96 trials) and 20\% were invalid (24 trials). Fearful and neutral face cues appeared 48 times on valid trials and 12 times on invalid trials. Participants could take a short break after each block. After the task, participants went through a 5-min recovery period. After the recovery period, participants completed the Spielberger State-Trait Anxiety Inventory (Spielberger, Gorsuch, \& Lushene, 1970) and the Penn State Worry Questionnaire (PSWQ; Meyer, Miller, Metzger, \& Borkovec, 1990).

\footnotetext{
${ }^{1}$ We tested only female subjects to avoid a potential gender effect (Koster et al., 2006).
} 
Materials. We selected 132 faces (66 with fearful facial expressions and 66 with neutral facial expressions; 33 females and 33 males with each expression) from the Karolinska Directed Emotional Faces set (Lundqvist, Flykt, \& Ohman, 1998), the NimStim Face Stimulus Set (Tottenham et al., 2009), the Cohn-Kanade AU-coded Facial Expression Database (Kanade, Cohn, \& Tian, 2000), the Ishai-NIMH set (Ishai, Pessoa, Bikle, \& Ungerleider, 2004), and Pictures of Facial Affect (Ekman \& Friesen, 1976). We used 120 faces (60 fearful and 60 neutral faces) for experimental trials and 12 faces for practice trials. All faces were converted to gray scale. Contrast and brightness were adjusted to maintain constancy across different face sets. As can be seen in Figure 1, each face was enclosed in a circular frame using Adobe PhotoShop CS3 software (Adobe System, San Jose, CA) to exclude nonfacial features (e.g., hair). In order to produce the HSF and LSF stimuli, the unfiltered (i.e., broad spatial frequency or BSF) pictures were filtered through a high-pass cut off of $>24$ cycles/image for the HSF stimuli and a low-pass cutoff of $<6$ cycles/image for the LSF stimuli. Average gray-scale values for the BSF, HSF, and LSF stimuli were 166, 168, and 158, respectively. For the neutral and fearful face categories, average gray-scale values were 164 and 168 , respectively, on a 256 gray-level scale. These average grayscale values did not significantly differ across spatial frequency, $F(2,357)=2.02, p=.13, \eta_{\mathrm{p}}^{2}=.01$, or emotional expression, $F(1$, $358)=1.10, p=.30, \eta_{\mathrm{p}}^{2}=.05$.

Physiological measurements. We recorded electrocardiographic activity via a standard three-electrode setup. The electrocardiography (ECG) signals, which were sampled at $1000 \mathrm{~Hz}$ (Task Force, 1996), passed through Mindware Technology's BioNex 50-3711-02 two-slot mainframe to an Optiplex GX620 personal computer (Pentium D, 2.80 GHz, 2.00 GB RAM) running Mindware Technology's BioLab 1.11 software, which received digital triggers (100-ms pulses) via a parallel port connection with a second Optiplex GX620 running E-Prime 1.1.4.1 (Psychology Software Tools, Inc.). The ECG signals were inspected offline using Mindware Technology's HRV 2.51 software, with which the ECG trace (plotted in $\mathrm{mV}$ against time) was carefully reexamined. Successive R spikes (identified by an automatic beat detection algorithm) were visually inspected. Successive IBIs (in ms) within the baseline period were written in a single text file and analyzed using the Kubios HRV analysis package $2.0,{ }^{2}$ through which time and frequency domain indices of the heart period power spectrum were computed. ${ }^{3}$ Time domain indices include estimates of rootmean-square successive difference in milliseconds (rMSSD) and heart rate (HR) in beats per minute. For spectral analyses, we used autoregressive estimates following the Task Force of the European Society of Cardiology and the North American Society of Pacing Electrophysiology guidelines (Task Force, 1996). We used rMSSD as the primary index of the cardiac vagal tone, as it is less affected by respiration (Penttilä et al., 2001). In addition, we used the central frequency of the HF power peak as an estimate of the respiration frequency (Thayer, Sollers, Ruiz-Padial, \& Vila, 2002).

Analyses. All analyses on reaction times (RTs) excluded incorrect trials and outliers (Fox et al., 2002). RTs of less than 150 $\mathrm{ms}$ (anticipatory responding), or more than $1,000 \mathrm{~ms}$ or three standard deviations above the mean (delayed responding), were considered outliers ( $2 \%$ of the data). The trimmed RTs were subjected to a 2 (HRV level: high, low) $\times 3$ (spatial frequency: broad, high, low $) \times 2$ (cue emotion: fearful, neutral $) \times 2$ (cue validity: valid, invalid) mixed factorial ANOVA. All variables were within-subjects, except for HRV level. In addition, Pearson correlations were used to examine the relationship between HRV as a continuous measure and attentional engagement and disengagement scores.

\section{Results}

Group characteristics. Following previous research (Hansen et al., 2003; Hansen, Johnsen, Sollers, Stenvik, \& Thayer, 2004; Johnsen et al., 2003; Ruiz-Padial, Sollers, Vila, \& Thayer, 2003; Thayer, Friedman, Borkovec, Johnsen, \& Molina, 2000), participants were divided into two groups — high or low HRV—-based on the median split of rMSSD during baseline (median $=39.86$; Hansen et al., 2003; Task Force, 1996; Thayer \& Lane, 2000). The high-HRV group $(M=57, S D=25)$ had significantly higher rMSSD than the low-HRV group $(M=23, S D=6), t(15.79)=$ $-5.28, p<.01, d=2.03$. The high-HRV group $(M=74, S D=$ 11) had significantly lower mean heart rate than the low-HRV group $(M=86, S D=12), t(27)=2.77, p=.01, d=1.07$. However, the two groups were not different in respiration when we examined the high-frequency peak $(\mathrm{Hz}), t(27)=.04, p=.97, d=$ $.14(M=.27, S D=.05$ for high-HRV group; $M=.27, S D=.05$ for low-HRV group). Likewise, the two groups did not differ on the PSWQ $(M=53, S D=13$ for high-HRV group; $M=50$, $S D=10$ for low-HRV group), the trait version of the STAI (STAI-trait; $M=40, S D=8$ for high-HRV group; $M=38$, $S D=8$ for low-HRV group), or the state version of the STAI (STAI-state; $M=42, S D=8$ for high-HRV group; $M=38, S D=$ 8 for low-HRV group) scores ( $p$ s $>.27$ ).

Reaction times. We hypothesized that (a) participants with low HRV would show faster engagement to LSF fearful faces than those with high HRV at short SOAs, and (b) there would be no HRV differences in attentional disengagement from HSF fearful faces. Replicating previous research with the emotional cueing task (Koster et al., 2004), there was a significant main effect for cue validity, $F(1,27)=135.03, p<.01, \eta_{\mathrm{p}}^{2}=.83$, such that RTs were faster following valid $(M=418, S D=36)$ compared with invalid cues $(M=458, S D=37)$. Replicating Fox and colleagues (2001), there was a significant main effect for cue emotion, $F(1$, 27) $=5.16, p<.05, \eta_{\mathrm{p}}^{2}=.16$, such that RTs following neutral face

\footnotetext{
${ }^{2}$ Program available at http://kubios.uef.fi/.

${ }^{3} \mathrm{HRV}$ can be measured in both time and frequency methods (Task Force, 1996). Time domain methods include the standard deviation of the interbeat intervals (IBIs), the mean square of the successive differences in rMSSD in IBIs, and the percentage of IBI differences greater than $50 \mathrm{~ms}$ (pNN50; Thayer \& Friedman, 2004; Task Force, 1996). In the frequency domain, the HR time series is decomposed into its frequency components, which can then be described in terms of a spectral density function that provides the distribution of power as a function of frequency (Berntson et al., 1997; Task Force, 1996; Thayer \& Friedman, 2004). The high frequency power (HFP) of HRV ranges from $0.15 \mathrm{~Hz}$ to $0.4 \mathrm{~Hz}$ and is exclusively mediated by the vagus nerve (Task Force, 1996; Thayer \& Friedman, 2004). The low-frequency band ranges from 0.04 to 0.15 , and is thought to reflect both sympathetic and vagal modulation on cardiac activity (Berntson et al., 1997; Task Force, 1996; Thayer \& Friedman 2004; Thayer, Friedman, \& Borkovec, 1996). High-frequency HRV power and rMSSD are considered to effectively quantify vagal activity (Buchheit Papelier, Laursen, \& Ahmaidi, 2007; Task Force, 1996; Thayer \& RuizPadial, 2006). In Experiment 1, rMSSD and log-transformed highfrequency HRV power were highly correlated, $r(29)=.83, p<.01$.
} 
cues were faster $(M=437, S D=35)$ than RTs following fearful face cues $(M=440, S D=35)$. These effects were qualified by a two-way interaction between cue validity and cue emotion, $F(1$, $27)=4.91, p<.05, \eta_{\mathrm{p}}^{2}=.15$; a three-way interaction between cue validity, cue emotion, and HRV level, $F(1,27)=4.83, p<.05$, $\eta_{\mathrm{p}}^{2}=.15$; and a four-way interaction between HRV level, spatial frequency, cue emotion, and cue validity, $F(2,54)=3.20, p<.05$, $\eta_{\mathrm{p}}^{2}=.11$ (see Table 1$)^{4}$

Attentional engagement and disengagement scores were computed to decompose the interaction. Following Koster and colleagues (2006), we computed indices for cue validity $\left(\mathrm{RT}_{\text {invalid cue }}-\mathrm{RT}_{\text {valid cue }}\right)$, attentional engagement $\left(\mathrm{RT}_{\text {valid }} /\right.$ neutral cue $-\mathrm{RT}_{\text {valid }} / \mathrm{fearful}$ cue), and attentional disengagement $\left(\mathrm{RT}_{\text {invalid }} /\right.$ fearful cue $-\mathrm{RT}_{\text {invalid }} /$ neutral cue) for each spatial frequency type. A positive cue validity score indicates attention toward a cue, whereas a negative cue validity score indicates attention away from a cue. A positive score on attentional engagement indicates faster attentional engagement by fearful cues compared with neutral cues, whereas a negative score indicates slower attentional engagement by fearful cues. A positive attentional disengagement score indicates slower attentional disengagement away from fearful cues, whereas a negative attentional disengagement score indicates faster attentional disengagement away from fearful cues.

To directly test our hypotheses, the engagement and disengagement scores of high- and low-HRV participants to different spatial frequency stimuli were subjected to a 2 (HRV level: high, low) $\times$ 3 (spatial frequency: broad, high, low) mixed factorial ANOVA. HRV level was a between-subjects factor, and spatial frequency was a within-subject factor. There was a significant interaction between HRV level and spatial frequency on engagement scores, $F(2,54)=4.51, p<.02, \eta_{\mathrm{p}}^{2}=.14 .^{5}$ As predicted, a planned comparison revealed that low-HRV participants showed faster attentional engagement to LSF fearful faces compared with highHRV participants, $F(1,27)=6.31, p<.02, \eta_{p}^{2}=.19$ (See Figure $3) .{ }^{6}$ Furthermore, HRV was negatively correlated with attentional engagement scores to LSF fearful faces, $r=-.40, p<.04$ (see Figure 4$){ }^{7}$ Thus, lower HRV was correlated with faster attentional engagement to LSF fearful faces. There was no significant difference in attentional engagement between high- and low-HRV participants to BSF or HSF fearful faces $(p s>.08)$. There was no significant main effect or interaction between spatial frequency and HRV in attentional disengagement ( $p s>.08)$. Consistent with our predictions, HRV was associated with attentional engagement to LSF fearful faces at short SOAs.

\section{Discussion}

In Experiment 1, we examined the relationship between individual differences in HRV and bottom-up processes associated with emotional attention. As expected, participants with low HRV show significantly faster attentional engagement to LSF fearful faces than participants with high HRV at short SOAs. Lower HRV was correlated with faster attentional engagement to LSF fearful faces. Faster attentional engagement to LSF fearful faces is considered dysfunctional because it may indicate an inflexible form of hypervigilance resulting from hyperactive amygdala activity (Brotman et al., 2010). In contrast, high HRV did not show faster attentional engagement to LSF fearful faces. It is possible that superior prefrontal inhibition associated with high HRV restrains hypervigilant amygdala responses to LSF fearful faces. Recent research suggests that amygdala responses to aversive stimuli (Cunningham, Van Bavel, \& Johnsen, 2008) and rapid attentional orienting (Brosch \& Van Bavel, 2012) are sensitive to top-down processes, suggesting that emotional attention may be flexible. As such, HRV is associated with bottom-up aspects of emotional attention. However, HRV may be associated with not only bottom-up but also top-down aspects of emotional attention. In Experiment 2, we explored the relationship between HRV and top-down aspects of emotional attention.

\section{Experiment 2: Cardiac Vagal Tone and Endogenous Emotional Attention}

We examined the relationship between individual differences in HRV and top-down processing associated with emotional attention during the endogenous attentional mode. Top-down, voluntary attentional control is exerted when the majority of the cues are valid at long SOAs (e.g., > 300 ms; Huang-Pollock \& Jigg, 2003; Posner \& Petersen, 1990). This experiment was designed to test whether HRV is associated with top-down processing involving emotional attention. We hypothesized that low-HRV participants would show delayed attentional disengagement from HSF fearful faces at 960-ms SOAs, although attentional engagement to LSF fearful faces would be less affected.

\section{Method}

Participants. Twenty-seven female undergraduate students (mean age $=20$ years) participated in the study for partial course credit. We followed the same procedure of recruiting participants as in Experiment 1. We excluded the data from two participants who had more than $15 \%$ of trials missing due to errors and outliers.

Design, stimuli, procedure, physiological measurements, analyses, and procedure. The design, stimuli, procedure, measures, and analyses were identical to Experiment 1, with the exception that SOAs were extended to $960 \mathrm{~ms}$. After a 1,000-ms initial fixation point, a face cue was presented either in a left- or right-side gray box for $300 \mathrm{~ms}$. After a 200-ms delay with the initial fixation display, the central fixation point was enlarged for $300 \mathrm{~ms}$, and then it returned to its original size. After a 160-ms delay, the target circle appeared at the center of either the left- or right-side boxes until the participants responded (or until 2,000 ms

\footnotetext{
${ }^{4}$ We also conducted a 2 (HRV level: high, low) $\times 3$ (spatial frequency: broad, high, low) $\times 2$ (cue emotion: fearful, neutral) $\times 2$ (cue validity: valid, invalid) mixed factorial ANOVA using log-transformed highfrequency HRV, another measure of vagally mediated HRV. Consistent with rMSSD data, the four-way interaction on the RT data was significant, $F(2,54)=3.44, p<.04, \eta_{\mathrm{p}}^{2}=.11$.

${ }^{5}$ When log-transformed high-frequency HRV was used, there was an interaction between HRV level and spatial frequency in the engagement scores, $F(2,54)=5.58, p<.01, \eta_{\mathrm{p}}^{2}=.17$.

${ }^{6}$ When we used log-transformed high-frequency HRV, a consistent result was found, $F(1,27)=8.28, p<.01, \eta_{\mathrm{p}}^{2}=.23$.

${ }^{7}$ The relationship was then subjected to a first-order partial correlation in order to explore the relationship controlling for the effect of respiration. The first-order correlation was found to be statistically significant, $r(26)=$ $-.39, p<.05$, indicating that a relationship between HRV and attentional engagement to LSF fearful faces exists after controlling for the effect of respiration.
} 
Table 1

Mean Correct Reaction Times (in Milliseconds) and Mean Cue Validity (in Milliseconds) as a Function of Emotion, Cue Validity $(C V)$ and Spatial Frequency, and Heart Rate Variability (HRV) Level in Experiment 1

\begin{tabular}{|c|c|c|c|c|c|c|}
\hline \multirow[b]{2}{*}{ Spatial frequency } & \multirow[b]{2}{*}{ Emotion } & \multirow[b]{2}{*}{ Cue validity } & \multicolumn{2}{|c|}{ High HRV $(n=14)$} & \multicolumn{2}{|c|}{ Low HRV $(n=15)$} \\
\hline & & & $M$ & CVI & $M$ & CVI \\
\hline \multirow[t]{4}{*}{ BSF } & \multirow[t]{2}{*}{ Fearful } & Valid & $398(31)$ & \multirow[t]{2}{*}{43} & $440(54)$ & \multirow[t]{2}{*}{32} \\
\hline & & Invalid & $441(39)$ & & $474(48)$ & \\
\hline & \multirow[t]{2}{*}{ Neutral } & Valid & $401(33)$ & \multirow[t]{2}{*}{33} & $432(48)$ & \multirow[t]{2}{*}{35} \\
\hline & & Invalid & $434(34)$ & & $467(53)$ & \\
\hline \multirow[t]{4}{*}{ HSF } & \multirow[t]{2}{*}{ Fearful } & Valid & $413(29)$ & \multirow[t]{2}{*}{35} & $430(44)$ & \multirow[t]{2}{*}{60} \\
\hline & & Invalid & 449 (37) & & $490(43)$ & \\
\hline & \multirow[t]{2}{*}{ Neutral } & Valid & $416(29)$ & \multirow[t]{2}{*}{39} & $432(42)$ & \multirow[t]{2}{*}{39} \\
\hline & & Invalid & $455(42)$ & & $471(42)$ & \\
\hline \multirow[t]{4}{*}{ LSF } & \multirow[t]{2}{*}{ Fearful } & Valid & $409(40)$ & \multirow[t]{2}{*}{37} & $419(29)$ & \multirow[t]{2}{*}{48} \\
\hline & & Invalid & $446(43)$ & & 467 (39) & \\
\hline & \multirow[t]{2}{*}{ Neutral } & Valid & $403(42)$ & \multirow[t]{2}{*}{43} & $424(37)$ & \multirow[t]{2}{*}{36} \\
\hline & & Invalid & $446(45)$ & & $461(33)$ & \\
\hline
\end{tabular}

Note. Standard deviations and the number of subjects in parentheses. Cue Validity Index (CVI) is estimated by contrasting the RTs for invalid cues with RTs for valid cues. BSF = broad spatial frequency; HSF = high spatial frequency; LSF = low spatial frequency; $\mathrm{RT}=$ reaction time.

elapsed). This resulted in a cue-target onset asynchrony (SOA) of $960 \mathrm{~ms}$. All analyses on RTs excluded incorrect trials and outliers ( $2 \%$ of the data).

\section{Results}

Group characteristics. Participants were divided into two groups - high or low HRV - based on the median split of rMSSD during baseline (median $=50.0$; Hansen et al., 2003; Task Force, 1996; Thayer \& Lane, 2000). ${ }^{8}$ The high-HRV group $(M=72$, $S D=20)$ had significantly higher rMSSD than the low-HRV group $(M=26, S D=13), t(23)=-6.64, p<.01, d=2.56$. The high-HRV group $(M=71, S D=11)$ had significantly lower mean heart rate than the low-HRV group $(M=88, S D=11), t(23)=$ $3.76, p<.01, d=1.45$. As in Experiment 1, two groups were not significantly different in respiration, $t(23)=-1.29, p=.21, d=$

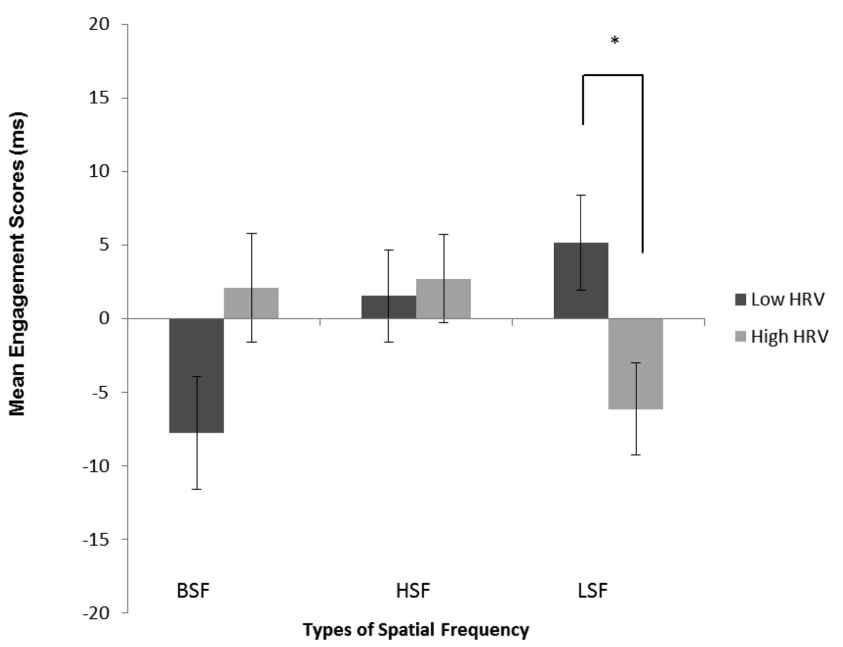

Figure 3. Mean engagement scores (in milliseconds) and standard errors of high- and low-HRV participants in response to cues of fearful faces at broad spatial frequency (BSF), high spatial frequency (HSF), and low spatial frequency (LSF) in Experiment 1. Note: ${ }^{*} p \leq .05$.
$.54(M=.27, S D=.06$ for high-HRV group; $M=.25, S D=.03$ for low-HRV group). Likewise, the two groups did not differ on the PSWQ $(M=56, S D=10$ for high-HRV group; $M=52$, $S D=16$ for low-HRV group), the trait version of the STAI (STAI-trait; $M=41, S D=8$ for high-HRV group; $M=44, S D=$ 12 for low-HRV group), or the state version of the STAI (STAIstate; $M=41, S D=10$ for high-HRV group; $M=44, S D=16$ for low-HRV group) scores ( $p$ s $>.44$ ).

Reaction times. The trimmed RTs were subjected to a 2 (HRV level: high, low) $\times 3$ (spatial frequency: broad, high, low) $\times$ 2 (cue emotion: fearful, neutral) $\times 2$ (cue validity: valid, invalid) mixed factorial ANOVA. All variables were within-subjects except for HRV level. We hypothesized that (a) there would be no difference between high- and low-HRV participants in attentional engagement, and (b) low-HRV participants would show significantly delayed attentional disengagement from HSF fearful faces compared with high-HRV participants.

Replicating Experiment 1 (see also Koster et al., 2004, 2006), a main effect of cue validity was significant, $F(1,23)=13.31, p<$ $.01, \eta_{\mathrm{p}}^{2}=.37$, indicating that RTs following valid cues were faster $(M=421, S D=39)$ than RTs following invalid cues $(M=432$, $S D=39)$. There was a significant four-way interaction between HRV level, spatial frequency, cue emotion, and cue validity, $F(2$, 46) $=3.37, p<.05, \eta_{\mathrm{p}}^{2}=.13$ (see Table 2). ${ }^{9}$ As in Experiment 1 , attentional engagement and disengagement scores were computed to decompose the four-way interaction.

To directly test our hypothesis, the engagement and disengagement scores of high- and low-HRV participants in different spatial frequency types were subjected to a 2 (HRV level: high and low) $\times$ 3 (spatial frequency: broad, high, low) mixed factorial ANOVA.

\footnotetext{
${ }^{8}$ In Experiment 2, rMSSD and log-transformed high-frequency HRV power were highly correlated, $r(25)=.88, p<.01$.

${ }^{9}$ We also conducted a 2 (HRV level: high, low) $\times 3$ (spatial frequency: broad, high, low) $\times 2$ (cue emotion: fearful, neutral) $\times 2$ (cue validity: valid, invalid) mixed ANOVA using log-transformed high-frequency $\mathrm{HRV}$, another measure of vagally mediated HRV. Consistent with rMSSD data, the four-way interaction on the RT data was significant, $F(2,46)=$ $4.12, p<.05, \eta_{\mathrm{p}}^{2}=.15$.
} 


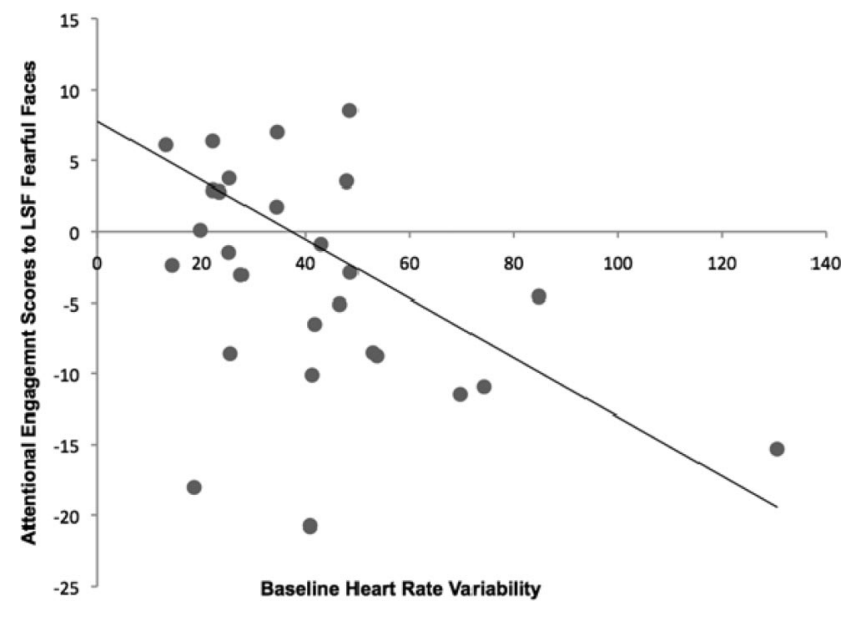

Figure 4. A scatterplot indicating the negative correlation between HRV ( $x$-axis) and attentional engagement scores (in milliseconds) to LSF faces (y-axis), $r=-.40, p=.02$.

HRV level was a between-subjects factor, and spatial frequency was a within-subject factor. There were no main effects or interaction on engagement scores ( $p$ s $>.27$ ).

However, consistent with our hypothesis that participants with low HRV would be related to slower attentional disengagement from HSF fearful faces at longer SOAs, there was a significant interaction between HRV level and spatial frequency on disengagement scores, $F(2,46)=3.69, p<.05, \eta_{\mathrm{p}}^{2}=.14{ }^{10}$ A planned comparison revealed that low-HRV participants were significantly slower to disengage attention from HSF fearful faces compared with high-HRV participants, $F(1,23)=6.64, p<.02, \eta_{p}^{2}=.22$ (see Figure 5). ${ }^{11}$ Furthermore, HRV was negatively correlated with attentional disengagement from HSF fearful faces, $r=-.39$, $p=.05$ (see Figure 6). ${ }^{12}$ Thus, lower HRV was correlated with slower attentional disengagement from HSF fearful faces. Additional analyses revealed that attentional disengagement did not differ between the two groups for BSF or LSF faces $(p s>.50)$. Therefore, consistent with our predictions, low-HRV participants showed significantly slower disengagement from HSF fearful faces compared with high-HRV participants, although differences between high- and low-HRV participants in attentional engagement to LSF fearful faces disappeared with the longer SOAs.

\section{Discussion}

In Experiment 2, we examined the relationship between individual differences in HRV and top-down aspects of emotional attention. As expected, low-HRV participants showed delayed attentional disengagement from HSF fearful faces. A recent study showed that low-HRV people had difficulty inhibiting their attention away from the location where HSF fearful faces were presented in an inhibition of return task (Park, Van Bavel, Vasey, \& Thayer, 2012b). Impaired attentional inhibition from HSF fearful faces exhibited by people with low HRV may, in part, be due to delayed attentional disengagement from them. In contrast, highHRV participants showed faster attentional disengagement from HSF fearful faces. However, there was no relationship between HRV and attentional engagement to LSF fearful faces. These results suggest that HRV was associated with top-down processing involving emotional attention, and that HSF information may be more susceptible to the top-down, endogenous attentional system. Taken together with Experiment 1, these studies provided evidence that HRV is associated with not only bottom-up but also top-down processing of emotional attention.

\section{General Discussion}

We examined individual differences in cardiac vagal tone-an index of cognitive and emotional self-regulation-and top-down and bottom-up processes involving emotional attention. In two experiments, we triggered either endogenous or exogenous attentional modes and presented faces at different spatial frequencies to help isolate the neurocognitive mechanisms underlying flexible emotional attention. As predicted, cardiac vagal tone was negatively associated with attentional engagement to LSF fearful stimuli under the exogenous attentional mode (Experiment 1) and positively associated with attentional disengagement from HSF fearful faces in the exogenous attentional mode (Experiment 2). These results are consistent with the idea that cardiac vagal tone is associated with the adaptive bottom-up and top-down modulation of emotional attention.

The current research not only provides an independent converging line of evidence for top-down and bottom-up processes associated with emotional attention but also elucidates that HRV is related to these processes. People with lower HRV seem to have more dysfunctional top-down and bottom-up emotional attention. The dysfunctional top-down and bottom-up cognitive processing may eventually lead to perseverative cognition (Brosschot, Gerin, \& Thayer, 2006; Friedman, 2007; Verkuil et al., 2009). Perseverative cognition can be defined as the constant activation of the cognitive representation of stress, and is considered a characteristic of various affective disorders, such as depression, anxiety disorders, and posttraumatic stress disorder (Brosschot, Pieper, \& Thayer, 2005; Thayer \& Friedman, 2004). Perseverative cognition, which often accompanies negative emotion, in turn, constantly activates physiological stress defense mechanisms, such as increases in HR and decreases in HRV, which will eventually "wear and tear" the system down (Brosschot et al., 2005). It has also been well documented that low levels of HRV are associated with physiological problems, such as hypertension, diabetes, high cholesterol, obesity, arthritis, and some cancers, as well as various affective disorders, including panic disorder and generalized anxiety disorders (Friedman \& Thayer, 1998; Thayer et al., 1996).

\footnotetext{
${ }^{10}$ When log-transformed high-frequency HRV was used, there was an interaction between HRV level and spatial frequency on disengagement scores, $F(2,46)=5.30, p<.01, \eta_{\mathrm{p}}^{2}=.19$.

${ }^{11}$ When log-transformed high-frequency HRV was used, a consistent result was obtained such that low-HRV participants showed significantly slower attentional disengagement from HSF fearful faces compared with high-HRV participants, $F(1,23)=8.63, p<.01, \eta_{\mathrm{p}}^{2}=.27$.

12 The relationship was then subjected to a first-order partial correlation in order to explore the relationship controlling for the effect of respiration. The first-order correlation was found to be statistically significant, $r(22)=$ $-.43, p<.04$, indicating that a relationship between HRV and attentional disengagement from HSF fearful faces exists after controlling for the effect of respiration.
} 
Table 2

Mean Correct Reaction Times (in Milliseconds) and Mean Cue Validity (in Milliseconds) as a Function of Emotion, Cue Validity (CV) and Spatial Frequency, and Heart Rate Variability (HRV) Level in Experiment 2

\begin{tabular}{|c|c|c|c|c|c|c|}
\hline \multirow[b]{2}{*}{ Spatial frequency } & \multirow[b]{2}{*}{ Emotion } & \multirow[b]{2}{*}{ Cue validity } & \multicolumn{2}{|c|}{ High HRV $(n=14)$} & \multicolumn{2}{|c|}{ Low HRV $(n=11)$} \\
\hline & & & $M$ & CVI & $M$ & CVI \\
\hline \multirow[t]{4}{*}{ BSF } & \multirow[t]{2}{*}{ Fearful } & Valid & $420(34)$ & \multirow[t]{2}{*}{11} & 412 (47) & \multirow[t]{2}{*}{12} \\
\hline & & Invalid & $431(38)$ & & $424(40)$ & \\
\hline & \multirow[t]{2}{*}{ Neutral } & Valid & $426(38)$ & \multirow[t]{2}{*}{6} & $410(42)$ & \multirow[t]{2}{*}{21} \\
\hline & & Invalid & $432(38)$ & & $430(45)$ & \\
\hline \multirow[t]{4}{*}{ HSF } & \multirow[t]{2}{*}{ Fearful } & Valid & $429(39)$ & \multirow[t]{2}{*}{8} & $417(41)$ & \multirow[t]{2}{*}{19} \\
\hline & & Invalid & 436 (34) & & $436(40)$ & \\
\hline & \multirow[t]{2}{*}{ Neutral } & Valid & $430(51)$ & \multirow[t]{2}{*}{18} & 418 (39) & \multirow[t]{2}{*}{5} \\
\hline & & Invalid & 448 (36) & & $423(26)$ & \\
\hline \multirow[t]{4}{*}{ LSF } & \multirow[t]{2}{*}{ Fearful } & Valid & 428 (37) & \multirow[t]{2}{*}{3} & 416 (37) & \multirow[t]{2}{*}{14} \\
\hline & & Invalid & $431(30)$ & & $430(48)$ & \\
\hline & \multirow[t]{2}{*}{ Neutral } & Valid & $435(38)$ & \multirow[t]{2}{*}{-3} & $422(39)$ & \multirow[t]{2}{*}{10} \\
\hline & & Invalid & $432(36)$ & & $432(37)$ & \\
\hline
\end{tabular}

Note. Standard deviations and the number of subjects in parentheses. BSF = broad spatial frequency; HSF = high spatial frequency; LSF $=$ low spatial frequency.

It has been suggested that perseverative cognition may result from a failure to exercise inhibitory prefrontal control over subcortical structures (Thayer \& Friedman, 2004). In the current research, low-HRV participants exhibited delayed disengagement from HSF fearful faces; it is possible that after an extended period of time, this may be the manifestation of perseverative cognition, such as chronic worry or rumination (Brosschot et al., 2006; Friedman, 2007; Verkuil et al., 2009). Likewise, in previous research, we showed that low-HRV participants had difficulty inhibiting their attention away from HSF

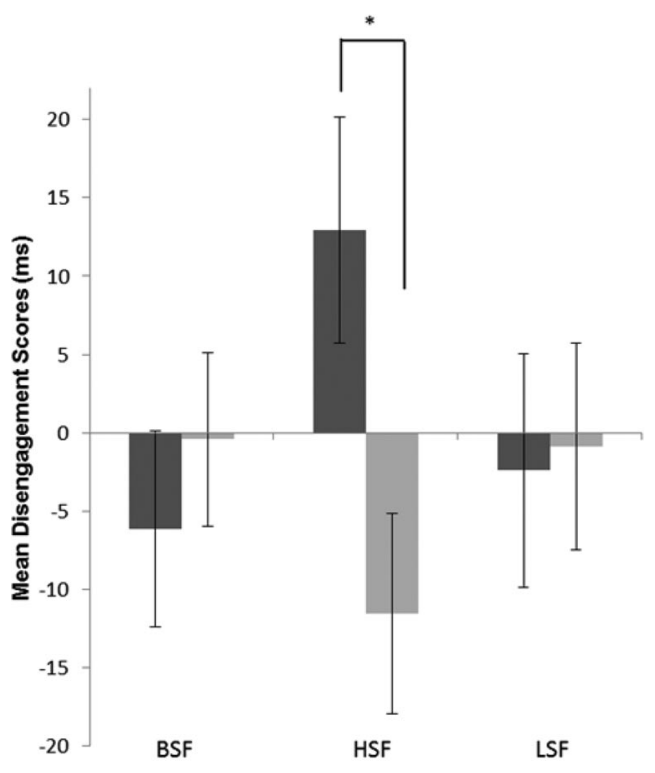

Types of Spatial Frequency

Figure 5. Mean disengagement scores (in milliseconds) and standard errors of high- and low-HRV participants in response to cues of fearful faces at broad spatial frequency (BSF), high spatial frequency (HSF), and low spatial frequency (LSF) in Experiment 2. Note: ${ }^{*} p \leq .05$. fearful faces in an inhibition of return task (Park et al., 2012b). Thus, our findings suggest that patterns related to perseverative cognition may be underlying this established association between low HRV and health problems.

There are some limitations of the current research. First of all, neuroimaging evidence will be necessary to further clarify our understanding of the relationship between top-down and bottom-up processing involved in emotional attention and differences in cardiac vagal tone. The current research suggests similar neural mechanisms may be implicated in mediating cardiac vagal tone and emotional attention. However, to explore this issue more directly, future research should use functional neuroimaging to isolate the specific brain regions implicated in emotional attention and cardiac vagal tone. Second, our participants were all female students, which makes it hard to generalize these results to male populations. Third, it has been suggested that delayed disengagement from threatening cues in the spatial cuing task may, in part, be due to greater slowing effects on motor responses when emotional cues were presented

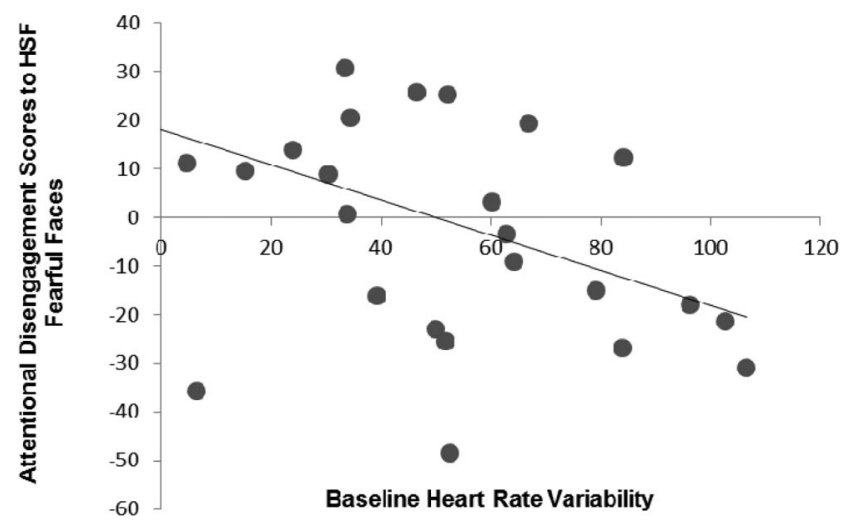

Figure 6. A scatterplot indicating the negative correlation between HRV $(x$-axis) and attentional engagement scores (in milliseconds) to HSF faces (y-axis), $r=-.39, p=.05$. 
for $200 \mathrm{~ms}$. However, it has yet to be determined whether slowing effects occur for high spatial frequency fearful faces for longer SOAs, as in the current study (i.e., $960 \mathrm{~ms}$ ).

It should be noted that we did not include positive stimuli in the current research because research suggests that increased cardiac vagal tone is associated with trait and state experiences of positive emotion (e.g., DiPietro, Porges, \& Uhly, 1992; Oveis et al., 2009). Therefore, the relationship between HRV and attentional engagement and disengagement of positive stimuli may be quite different from what we observed with fearful faces, which we felt should be examined separately.

\section{Conclusions}

The current research provides evidence that cardiac vagal tone is essential to the top-down and bottom-up processing associated with emotional attention. We found that cardiac vagal tone is associated with flexible emotional attention that appears to be situationally adaptive. We speculate that functional emotional attention may support successful self-regulation in a variety of contexts. If so, behavioral and clinical deficits in people with low cardiac vagal tone may stem from inflexible or maladaptive emotional attention.

\section{References}

Ahern, G. L., Sollers, J. J., Lane, R. D., Labiner, D. M., Herring, A. M., Weinand, M. E., . . . Thayer, J. F. (2001). Heart rate and heart rate variability changes in the intracarotid sodium amobarbital (ISA) test. Epilepsia, 42, 912-921. doi:10.1046/j.1528-1157.2001.042007912.x

American Psychiatric Association. (1994). Diagnostic and statistical manual of mental disorders (4th ed.). Washington, DC: American Psychiatric Association.

Bannerman, R. L., Hibbard, P. B., Chalmers, K., \& Sahraie, A. (2012). Saccadic latency is modulated by emotional content of spatially filtered face stimuli. Emotion, 12, 1384-1392. doi:10.1037/a0028677

Bar-Haim, Y., Lamy, D., Pergamin, L., Bakermans-Kranenburg, M. J., \& van Ijzendoorn, M. H. (2007). Threat-related attentional bias in anxious and nonanxious individuals: A meta-analytic study. Psychological Bulletin, 133, 1-24. doi:10.1037/0033-2909.133.1.1

Bartolomeo, P., Sieroff, E., Decaix, C., \& Chokron, S. (2001). Modulating the attentional bias in unilateral neglect: The effects of the strategic set. Experimental Brain Research. Experimentelle Hirnforschung. Expérimentation cérébrale, 137, 432-444. doi:10.1007/s002210000642

Benarroch, E. (1993). The central autonomic network: Functional organization, dysfunction, and perspective. Mayo Clinic Proceedings, 68, 988-1001. doi:10.1016/S0025-6196(12)62272-1

Berger, A., Henik, A., \& Rafal, R. (2005). Competition between endogenous and exogenous orienting of visual attention. Journal of Experimental Psychology: General, 134, 207-221. doi:10.1037/0096-3445.134.2 207

Berntson, G. G., Bigger, J. T., Eckberg, D. L., Grossman, P., Kaufmann, P. G., Malik, M., . . . Van Der Molen, M. W. (1997). Heart rate variability: Origins, methods, and interpretive caveats. Psychophysiology, 34, 623-648. doi:10.1111/j.1469-8986.1997.tb02140.x

Brosch, T., \& Van Bavel, J. J. (2012). The flexibility of emotional attention: Accessible social identities guide rapid attentional orienting. Cognition, 125, 309-316. doi:10.1016/j.cognition.2012.07.007

Brosschot, J. F., Gerin, W., \& Thayer, J. F. (2006). The perseverative cognition hypothesis: A review of worry, prolonged stress-related physiological activation, and health. Journal of Psychosomatic Research, 60, 113-124. doi:10.1016/j.jpsychores.2005.06.074
Brosschot, J. F., Pieper, S., \& Thayer, J. F. (2005). Expanding stress theory: Prolonged activation and perseverative cognition. Psychoneu roendocrinology, 30, 1043-1049. doi:10.1016/j.psyneuen.2005.04.008

Brotman, M. A., Rich, B. A., Guyer, A. E., Lunsfoird, J. R., Horsey, S. E., Reising, M. M., . . . Towbin, K. (2010). Amygdala activation during emotion processing of neutral faces in children with severe mood dysregulation versus ADHD or bipolar disorder. The American Journal of Psychiatry, 167, 61-69.

Buchheit, M., Papelier, Y., Laursen, P. B., \& Ahmaidi, S. (2007). Noninvasive assessment of cardiac parasympathetic function: Postexercise heart rate recovery or heart rate variability? American Journal of Physiology: Heart and Circulatory Physiology, 293, H8-H10. doi:10.1152/ ajpheart.00335.2007

Cisler, J. M., \& Koster, E. H. W. (2010). Mechanisms of attentional biases towards threat in anxiety disorders: An integrative review. Clinical Psychology Review, 30, 203-216. doi:10.1016/j.cpr.2009.11.003

Coull, J. T., Frith, C. D., Buchel, C., \& Nobre, A. C. (2000). Orienting attention in time: Behavioral and neuroanatomical distinction between exogenous and endogenous shifts. Neuropsychologia, 38, 808-819. doi:10.1016/S0028-3932(99)00132-3

Cunningham, W. A., Van Bavel, J. J., \& Johnsen, I. R. (2008). Affective flexibility: Evaluative processing goals shape amygdala activity. Psychological Science, 19, 152-160. doi:10.1111/j.1467-9280.2008 .02061.x

Cunningham, W. A., Zelazo, P. D., Packer, D. J., \& Van Bavel, J. J. (2007). The iterative reprocessing model: A multi-level framework for attitudes and evaluation. Social Cognition, 25, 736-760. doi:10.1521/soco.2007 25.5.736

DiPietro, J. A., Porges, S. W., \& Uhly, B. (1992). Reactivity and developmental competence in preterm and full-term infants. Developmental Psychology, 28, 831-841. doi:10.1037/0012-1649.28.5.831

Ekman, P., \& Friesen, W. V. (1976). Pictures of facial affect. Palo Alto, CA: Consulting Psychologists Press.

Ellis, R. J., \& Thayer, J. F. (2010). Music and autonomic nervous system (dys)function. Music Perception, 27, 317-326. doi:10.1525/mp.2010.27 .4 .317

Fox, E., Russo, R., Bowles, R., \& Dutton, K. (2001). Do threatening stimuli draw or hold visual attention in subclinical anxiety. Journal of Experimental Psychology: General, 130, 681-700. doi:10.1037/00963445.130.4.681

Fox, E., Russo, R., \& Dutton, K. (2002). Attentional bias for threat: Evidence for delayed disengagement from emotional faces. Cognition and Emotion, 16, 355-379. doi:10.1080/02699930143000527

Friedman, B. H. (2007). An autonomic flexibility-neurovisceral integration model of anxiety and cardiac vagal tone. Biological Psychology, 74, 185-199. doi:10.1016/j.biopsycho.2005.08.009

Friedman, B. H., \& Thayer, J. F. (1998). Autonomic balance revisited: Panic anxiety and heart rate variability. Journal of Psychosomatic Research, 44, 133-151. doi:10.1016/S0022-3999(97)00202-X

Hansen, A. L., Johnsen, B. H., Sollers, J. J., Stenvik, K., \& Thayer, J. F. (2004). Heart rate variability and its relation to prefrontal cognitive function: The effects of training and detraining. European Journal of Applied Physiology, 93, 263-272. doi:10.1007/s00421-004-1208-0

Hansen, A. L., Johnsen, B. H., \& Thayer, J. F. (2003). Vagal influence on working memory and attention. International Journal of Psychophysiology, 48, 263-274. doi:10.1016/S0167-8760(03)00073-4

Holmes, A., Green, S., \& Vuilleumier, P. (2005). The involvement of distinct visual channels in rapid attention towards fearful facial expressions. Cognition and Emotion, 19, 899-922. doi:10.1080/ 02699930441000454

Hsu, S.-M., \& Pessoa, L. (2007). Dissociable effects of bottom-up and top-down factors in the processing of unattended fearful faces. Neuropsychologia, 45, 3075-3086. doi:10.1016/j.neuropsychologia.2007.05 .019 
Huang-Pollock, C. L., \& Jigg, J. L. (2003). Searching for the attention deficit in attention deficit hyperactivity disorder: The case of visuospatial orienting. Clinical Psychology Review, 23, 801-830. doi:10.1016/ S0272-7358(03)00073-4

Ishai, A., Pessoa, L., Bikle, P. C., \& Ungerleider, L. G. (2004). Repetition suppression of faces is modulated by emotion. Proceedings of the National Academy of Sciences of the United States of America, 101, 9827-9832

Johnsen, B. H., Thayer, J. F., Laberg, J. C., Wormnes, B., Raadal, M., Skaret, E., Kvale, G., \& Berg, E. (2003). Attentional and physiological characteristics of patients with dental anxiety. Journal of Anxiety Disorders, 17, 75-87. doi:10.1016/S0887-6185(02)00178-0

Johnstone, T., van Reekum, C. M., Urry, H. L., Kalin, N. H., \& Davidson, R. J. (2007). Failure to regulate: Counterproductive recruitment of top-down prefrontal-subcortical circuitry in major depression. The Journal of Neuroscience, 27, 8877-8884. doi:10.1523/JNEUROSCI.206307.2007

Kanade, T., Cohn, J. F., \& Tian, Y. (2000). Comprehensive database for facial expression analysis. In Proceedings of the Fourth IEEE International Conference on Automatic Face and Gesture Recognition (pp. 46-53). Los Alamitos, CA: IEEE Computer Society Conference Publishing Services.

Koster, E. H. W., Crombez, G., Verschuere, B., Damme, S. V., \& Wiersema, J. R. (2006). Components of attentional bias to threat in high trait anxiety: Facilitated engagement, impaired disengagement, and attentional avoidance. Behaviour Research and Therapy, 44, 1757-1771. doi:10.1016/j.brat.2005.12.011

Koster, E. H. W., Crombez, G., Verschuere, B., \& Houwer, J. D. (2004). Selective attention to threat in the dot probe paradigm: Differentiating vigilance and difficulty to disengage. Behaviour Research and Therapy, 42, 1183-1192. doi:10.1016/j.brat.2003.08.001

Lane, R. D., McRae, K., Reiman, E. M., Chen, K., Ahern, G. L., \& Thayer, J. F. (2009). Neural correlates of heart rate variability during emotion. NeuroImage, 44, 213-222. doi:10.1016/j.neuroimage.2008.07.056

Livingstone, M., \& Hubel, D. (1988). Segregation of form, color, movement, and depth: Anatomy, physiology, and perception. Science, 240, 740-749. doi:10.1126/science. 3283936

Lundqvist, D., Flykt, A., \& Ohman, A. (1998). The Karolinska Directed Emotional Faces (KDEF). Karolinska Institute. Retrieved from http:// www.emotionlab.se/resources/kdef

Mathews, A., Mackintosh, B., \& Fulcher, E. P. (1997). Cognitive biases in anxiety and attention to threat. Trends in Cognitive Sciences, 1, 340345. doi:10.1016/S1364-6613(97)01092-9

Merigan, W. H., \& Maunsell, J. H. R. (1993). How parallel are the primate visual pathways. Annual Review of Neuroscience, 16, 369-402. doi: 10.1146/annurev.ne.16.030193.002101

Meyer, T. J., Miller, M. L., Metzger, R. L., \& Borkovec, T. D. (1990). Development and validation of the Penn State Worry Questionnaire. Behaviour Research and Therapy, 28, 487-495. doi:10.1016/00057967(90)90135-6

Morrison, D. J., \& Schyns, P. G. (2001). Usage of spatial scales for the categorization of faces, objects, and scenes. Psychonomic Bulletin \& Review, 8, 454-469. doi:10.3758/BF03196180

Müller, H. J., \& Rabbitt, J. M. (1989). Reflexive and voluntary orienting of visual attention: Time course of activation and resistance to interruption. Journal of Experimental Psychology: Human Perception and Performance, 15, 315-330. doi:10.1037/0096-1523.15.2.315

Nieuwenhuis, S., Jepma, M., Fors, S. L., \& Olivers, C. N. L. (2008). The role of the magnocellular and parvocellular pathways in the attentional blink. Brain and Cognition, 68, 42-48. doi:10.1016/j.bandc.2008.02 119

Ochsner, K. N., \& Gross, J. J. (2005). The cognitive control of emotion. Trends in Cognitive Sciences, 9, 242-249. doi:10.1016/j.tics.2005.03 .010
Ochsner, K. N., Ray, R., Robertson, E., Cooper, J., Gross, J. J., \& Gabrieli, J. D. E. (2009). Bottom-up and top-down processes in emotion generation. Psychological Science, 20, 1322-1331. doi:10.1111/j.1467-9280 2009.02459.x

Oveis, C., Cohen, A. B., Gruber, J., Shiota, M. N., Haidt, J., \& Keltner, D. (2009). Resting respiratory sinus arrhythmia is associated with tonic positive emotionality. Emotion, 9, 265-270. doi:10.1037/a0015383

Palermo, R., \& Rhodes, G. (2007). Are you always on my mind? A review of how face perception and attention interact. Neuropsychologia, 45, 75-92. doi:10.1016/j.neuropsychologia.2006.04.025

Park, G., Van Bavel, J. J., Egan, E. J. L., Vasey, M. W., \& Thayer, J. F. (2012a). From the heart to the mind's eye: Cardiac vagal tone is related to visual perception of fearful faces at high spatial frequency. Biological Psychology, 90, 171-178. doi:10.1016/j.biopsycho.2012.02.012

Park, G., Van Bavel, J. J., Vasey, M. W., \& Thayer, J. F. (2012b). Cardiac vagal tone predicts inhibited attention to fearful faces. Emotion, 12, 1292-1302. doi:10.1037/a0028528

Park, G., Vasey, M., Van Bavel, J. J., \& Thayer, J. F. (2013). Cardiac vagal tone is correlated with selective attention to neutral distractors under load. Psychophysiology, 50, 398-406. doi:10.1111/psyp.12029

Parker, D. M., Lishman, J. R., \& Hughes, J. (1996). Role of course and fine spatial information in face and object processing. Journal of Experimental Psychology: Human Perception and Performance, 22, 1448-1466. doi:10.1037/0096-1523.22.6.1448

Penttilä, J., Helminen, A., Jartti, T., Kuusela, T., Huikuri, H. V., Tulppo, M. P., . . Scheinin, H. (2001). Time domain, geometrical and frequency domain analysis of cardiac vagal outflow: Effects of various respiratory patterns. Clinical Physiology, 21, 365-376. doi:10.1046/j.1365-2281 2001.00337.x

Pessoa, L., Kastner, S., \& Ungerleider, L. G. (2002). Attentional control of the processing of neutral and emotional stimuli. Cognitive Brain Research, 15, 31-45. doi:10.1016/S0926-6410(02)00214-8

Porges, S. W. (1991). Vagal tone: An autonomic mediator of affect. In J. A. Garber \& K. A. Dodge (Eds.), The development of affect regulation and dysregulation (pp. 111-128). New York, NY: Cambridge University Press. doi:10.1017/CBO9780511663963.007

Porges, S. W. (2003). The polyvagal theory: Phylogenetic contributions to social behavior. Physiology \& Behavior, 79, 503-513. doi:10.1016/ S0031-9384(03)00156-2

Posner, M. I., \& Petersen, S. E. (1990). The attention system of the human brain. Annual Review of Neuroscience, 13, 25-42. doi:10.1146/annurev .ne.13.030190.000325

Posner, M. I., \& Rothbart, M. K. (2007). Networks as a model for the integration of psychological science. Annual Review of Psychology, 58, 1-23. doi:10.1146/annurev.psych.58.110405.085516

Pourtois, G., Dan, E. S., Grandjean, D., Sander, D., \& Vuilleumier, P. (2005). Two electrophysiological stages of spatial orienting towards fear faces: Early temporo-parietal activation preceding gain control in extrastriate visual cortex. NeuroImage, 26, 149-163. doi:10.1016/j neuroimage.2005.01.015

Pourtois, G., \& Vuilleumier, P. (2006). Dynamics of emotional effects on spatial attention in the human visual cortex. Progress in Brain Research, 156, 67-91. doi:10.1016/S0079-6123(06)56004-2

Ruiz-Padial, E., Sollers, J. J., Vila, J., \& Thayer, J. F. (2003). The rhythm of the heart in the blink of an eye: Emotion-modulated startle magnitude covaries with heart rate variability. Psychophysiology, 40, 306-313. doi:10.1111/1469-8986.00032

Spielberger, C. D., Gorsuch, R. L., \& Lushene, R. E. (1970). Manual for the State-Trait Inventory. Palo Alto, CA: Consulting Psychologists.

Task Force of the European Society of Cardiology and the North American Society of Pacing and Electrophysiology. (1996). Heart rate variability: Standards of measurement, physiology interpretation, and clinical use. Circulation, 93, 1043-1065. doi:10.1161/01.CIR.93.5.1043

Thayer, J. F., \& Friedman, B. H. (2004). A neurovisceral integration model 
of health disparities in aging. In N. B. Anderson, R. A. Bulatao, and B. Cohen (Eds.), Critical perspective on racial and ethnic differences in health in late life (pp. 567-603). Washington, DC: The National Academies Press.

Thayer, J. F., Friedman, B. H., \& Borkovec, T. D. (1996). Autonomic characteristics of generalized anxiety disorder and worry. Biological Psychiatry, 39, 255-266. doi:10.1016/0006-3223(95)00136-0

Thayer, J. F., Friedman, B. H., Borkovec, T. D., Johnsen, B. H., \& Molina, S. (2000). Phasic heart period reactions to cued threat and non-threat stimuli in generalized anxiety disorder. Psychophysiology, 37, 361-368. doi:10.1111/1469-8986.3730361

Thayer, J. F., Hansen, A. L., Saus-Rose, E., \& Johnsen, B. H. (2009). Heart rate variability, prefrontal neural function and cognitive performance: The neurovisceral integration perspective on self-regulation, adaptation, and health. Annals of Behavioral Medicine, 37, 141-153. doi:10.1007/ s12160-009-9101-Z

Thayer, J. F., \& Lane, R. D. (2000). A model of neurovisceral integration in emotion regulation and dysregulation. Journal of Affective Disorders, 61, 201-216. doi:10.1016/S0165-0327(00)00338-4

Thayer, J. F., \& Ruiz-Padial, E. (2006). Neurovisceral integration, emotions and health: An update. International Congress Series, 1287, 122127. doi:10.1016/j.ics.2005.12.018

Thayer, J. F., Sollers, J. J., III, Ruiz-Padial, E., \& Vila, J. (2002). Estimating respiratory frequency from autoregressive spectral analysis of heart period. IEEE Engineering in Medicine and Biology Magazine, 21, 4145. doi:10.1109/MEMB.2002.1032638

Tottenham, N., Tanaka, J., Leon, A. C., McCarry, T., Nurse, M., \& Hare, T. A. (2009). The NimStim set of facial expressions: Judgments from untrained research participants. Psychiatry Research, 168, 242-249
Van Bavel, J. J., Xiao, Y. J., \& Cunningham, W. A. (2012). Evaluation is a dynamic process: Moving beyond dual system models. Social and Personality Psychology Compass, 6, 438-454. doi:10.1111/j.1751-9004 .2012.00438.x

Verkuil, B., Brosschot, J. E., Putman, P., \& Thayer, J. F. (2009). Interacting effects of worry and anxiety on attentional disengagement from threat. Behaviour Research and Therapy, 47, 146-152. doi:10.1016/j .brat.2008.11.003

Vuilleumier, P. (2005). How brains beware: Neutral mechanisms of emotional attention. Trends in Cognitive Sciences, 9, 585-594. doi:10.1016/ j.tics.2005.10.011

Vuilleumier, P., Armony, J. L., Driver, J., \& Dolan, R. J. (2003). Distinct spatial frequency sensitivities for processing faces and emotional expressions. Nature Neuroscience, 6, 624-631. doi:10.1038/nn1057

Vuilleumier, P., \& Brosch, T. (2009). Interactions of emotion and attention. In M. S. Gazzaniga (Ed.), The cognitive neurosciences IV (pp. 925-934). Cambridge, MA: MIT Press.

Vuilleumier, P., \& Huang, Y.-M. (2009). Emotional attention: Uncovering the mechanisms of affective biases in perception. Current Directions in Psychological Science, 18, 148-152. doi:10.1111/j.1467-8721.2009 .01626.x

Winston, J. S., Vuilleumier, P., \& Dolan, R. (2003). Effects of low-spatial frequency components of fearful faces on fusiform cortex activity. Current Biology, 13, 1824-1829. doi:10.1016/j.cub.2003.09.038

Received June 19, 2012

Revision received February 8, 2013 Accepted February 11, 2013 